\title{
Spectroscopic Studies of Nanocomposites Based on PEO/PVDF Blend Loaded by SWCNTS
}

\author{
Hind Mohammed Alhusiki-Alghamdi, Naziha Suliman Alghunaim* \\ Department of Physics, Faculty of Science for Girls, King Abdulaziz University, Jeddah, Saudi Arabia \\ Email: om bushra@yahoo.com, ${ }^{*}$ n-al-ghunaim@hotmail.com
}

Received 3 March 2015; accepted 17 March 2015; published 19 March 2015

Copyright (C) 2015 by authors and Scientific Research Publishing Inc.

This work is licensed under the Creative Commons Attribution International License (CC BY). http://creativecommons.org/licenses/by/4.0/

(c) (i) Open Access

\begin{abstract}
Novel nanocomposites of PEO/PVDF loaded by different contents of SWCNTs were prepared. From UV-Vis spectra, the estimated values of absorption edge, absorption coefficient, energy of tail and extinction coefficient were calculated. The exponential decay tail at low energy is due to the presence of localized states in the energy band gap. The shift of Raman spectra indicates the possibility of SWCNTs to be attached with $\mathrm{OH}$ group in the side chain of polymer molecules. The X-ray measurements indicate that the addition of SWCNTs is a rich amorphous region in polymeric matrices and complete complexation between PEO/PVDF blend and SWCNTs. The SEM images show smooth surface of PEO/PVDF and they become rough with single rod with a good distribution within surface region in polymeric matrices after loading SWCNTs. TEM images showed that SWCNTs were dispersed well in polymeric matrices. The broken ends of nanotubes were showing that the SWCNTs were broken apart rather than from at the fracture surface. The films show some defects like rags on the tube walls. There are some black regions in TEM images attributed to amorphous nature carbon. The prepared nanocomposites are very useful in technical application.
\end{abstract}

\section{Keywords}

SWCNTs, Nanocomposites, UV-Vis Spectroscopy, Raman Shift, TEM

\section{Introduction}

In general, nanofillers play roles in improvement and modification for properties of polymer and/or polymer blend and they reduce the cost of their nanocomposites [1]. In classical nanocomposites, inorganic materials used

${ }^{*}$ Corresponding author. 
as a filler with dimensions in nanometer range have been used to enhance properties of pure blend. Indeed, the properties of nanocomposites are designed by different parameters, such as different sizes, shapes and volumes of the nanofillers as a filler [2] [3]. More enhancements of the nanocomposite properties can be improved by loading nanofiller materials with aspect ratio [4]-[6]. Novel nanoparticles with polymer at low ratio are promising reinforcement materials. The well dispersion of the polymer using nanoparticles is poor, indicating that they are incompatible with each other. So, the compatibility and the surface of the additions still need improvements in the preparation at the dispersion.

Single walled carbon nanotubes (SWCNTs) have attracted scientific and technological research worldwide, since they arc evaporation of graphite with helium atmosphere [7]. CNTs can be classified into carbon nanofibers, single walled nanotubes and multi walled nanotubes [8]. SWCNT with low diameter consists of a single layer of graphene which is wrapped into a cylindrical shape [9]. There are three classes of SWNTs depending on arrangement of in the hexagons and pentagon structures, namely, armchair, zigzag and chiral. The MWCNTs contain a large number of graphene layers which are rolled together. Any carbon atom in a graphene layer is bonded by covalent bonds with neighbor carbon atoms [10]. There are three orbitals $\left(\mathrm{sp}^{2}\right)$ form $\sigma$-bonds with the other carbon atoms. On each carbon, unique orbital $(2 \mathrm{p})$ remains un-hybridized. These orbitals, $\mathrm{sp}^{2}$ and $2 \mathrm{p}$, are combined to form the $\pi$-bonds.

Polymer nanocomposite is a new class of material alternative to the conventional filled polymers. Nanosized of inorganic fillers are dispersed in polymer matrix give trend to accessing of major improvement to performance properties of the pure polymer. Polymer nanocomposites with SWCNTs as good fillers have received attention for their wide use in electronic, thermal, and mechanical properties [11] [12]. The main goal of this work is to report investigations and characterization carried out by UV-Vis spectroscopy, X-ray, Raman, SEM and TEM spectroscopy on PEO/PVDF blend and PEO/PEVDF loaded by different content of SWCNTs nanocomposites.

\section{Experimental}

\section{Materials}

Polyethylene oxide (PEO) with molecular weight $\approx 900000$ obtained from ACROS (New Jersey, USA) and polyvinylidene fluoride (PVDF) of molecular weight $\approx 180000$ supplied from Aldrich, USA. Single walled carbon nanotubes (SWCNTs) with $\mathrm{COOH}$ functional groups (NTX10) were obtained from Nanothinx, Greece. CNTs$\mathrm{COOH}$ has diameter $8-14 \mathrm{~nm}$, length $\geq 5 \mu \mathrm{m}$ and purity $88 \%$.

The PEO and PVDF were dried at $60^{\circ} \mathrm{C}$ in a vacuum oven about $1 \mathrm{~h}$ to remove any moisture. Amount of both PEO and PVDF (1: 4) was dissolved in Dimethyl sulfoxide (DMSO) as a solvent. The blend solutions with good viscosity were obtained. The SWCNTs-COOH was added separately to $10 \mathrm{ml}$ DMSO on a beaker. The beaker was immersed, to give suspension; in on the ultrasonic (Eltrosonic type-07) about $40 \mathrm{~min}$. The PEO/PVDF nanocomposites containing SWCNTs were prepared using casting method by adding SWCNTs solution drop wise to blend solution with continuous stirring. The concentration of SWCNTs namely, 0.05 and $0.1 \mathrm{wt} \%$. After careful mixing of SWCNTs dispersions with blend solution followed by casting of PEO/PVDF/SWCNTs nanocomposite films were obtained by peeling off from PET dishes and put it at $60^{\circ} \mathrm{C}$ in a vacuum oven to evaporate the solvent $\approx 48 \mathrm{~h}$. The prepared samples kept in a vacuum desiccator before measurement. The thickness of the obtained films is nearly $20 \mu \mathrm{m}$.

The UV-Visible absorption spectra were measured in the wavelength region of $200-2000 \mathrm{~nm}$ using spectrophotometer (V-570 UV-VIS-NIR, JASCO, Japan). The Raman spectra were recorded in the backscattering geometry on a Labram HR (Jobin-Yvon, Horiba Group, France) microspectrometer using $50 \mathrm{~mW}$ power laser with 532 $\mathrm{nm}$. The X-Ray diffraction scans were obtained using DIANO corporation-USA equipped using $\mathrm{Cu}-\mathrm{K} \alpha$ radiation $\left(\lambda=1.540 \AA\right.$, the tube operated at $30 \mathrm{kV}$, the Bragg angle $(2 \theta)$ in the range of $5^{\circ}-60^{\circ}$. Scanning electron micrograph was conducted using SEM (JEOL-JSM 6100) with $30 \mathrm{KV}$ operating voltage. Transmission electron microscope (JEOL-JEM-1011, Japan) was carry out to estimate the diameter, shape, length and well distribution of the nanoparticles within the polymeric matrix. The samples for TEM were prepared by dropping the ethanol suspension of SWCNTs onto a grid which was left to air-dry about $30 \mathrm{~min}$.

\section{Results and Discussion}

\subsection{Ultraviolet-Visible Spectroscopy (UV-Vis)}

The Ultraviolet-Visible absorption spectra of PEO/PVDF blend and the blend loaded with 0.05 and $0.1 \mathrm{Wt} \%$ of 
SWCNTs in the range of $200-2000 \mathrm{~nm}$ at room temperature are shown in Figure 1. All UV-Vis curves are characterized by exponentially decay tail at lower energy due to localized states in the optical energy band gap and also indicating presence of amorphousregion of the samples. The origin of this band tailing is still a matter of conjecture but according to Dow and Redfield [13].

It is observed in these spectra that each spectrum exhibit prominent peak at $\approx 254 \mathrm{~nm}$ due to $\mathrm{n} \rightarrow \pi^{*}$ (Rband) electronic transitions. Moreover, there are no absorption bands on the visible region for all samples since the films are transparent [14].

The absorption coefficient $(\alpha)$ near the edge can be directly determined from the absorbance results using the following formula [15]:

$$
\alpha=\frac{2.303 A}{d}
$$

where $d$ is the thickness of the sample and $A$ is the absorbance $\left(A=\log _{10}\left(\frac{I_{o}}{I}\right)\right)$; where $I_{o}$ and $I$ are the intensity of photon striking and emerging from the sample, respectively.

The plot of absorption coefficient $(\alpha)$ as a function $h v$ for the samples is shown in Figure 2. The plot exhibit different slopes indicating the probability of the presence of different transitions in nanocomposite samples. The falling in the edges at lower photon energy region indicating the lack of long range order andirregular fluctuations of internal fields associated with disorder of the structure in the prepared samples. The absorptionedge for all samples is increases with increase SWCNTs content.

The extinction coefficient $(k)$ is estimated from the equation [16]:

$$
k=\frac{\alpha \lambda}{4 \pi}
$$

where $\lambda$ is the wavelength of incident photon. The plot of the extinction coefficient $(k)$ as a function of $h v$ is shown in Figure 3. All spectrum show an increases of $k$ with increase in $h v$ attributed to the probability of electron transfer across the mobility rises with photon energy.

According to Tauc et al. [17], three distinct regions are observed in the absorption spectrum. The first is the

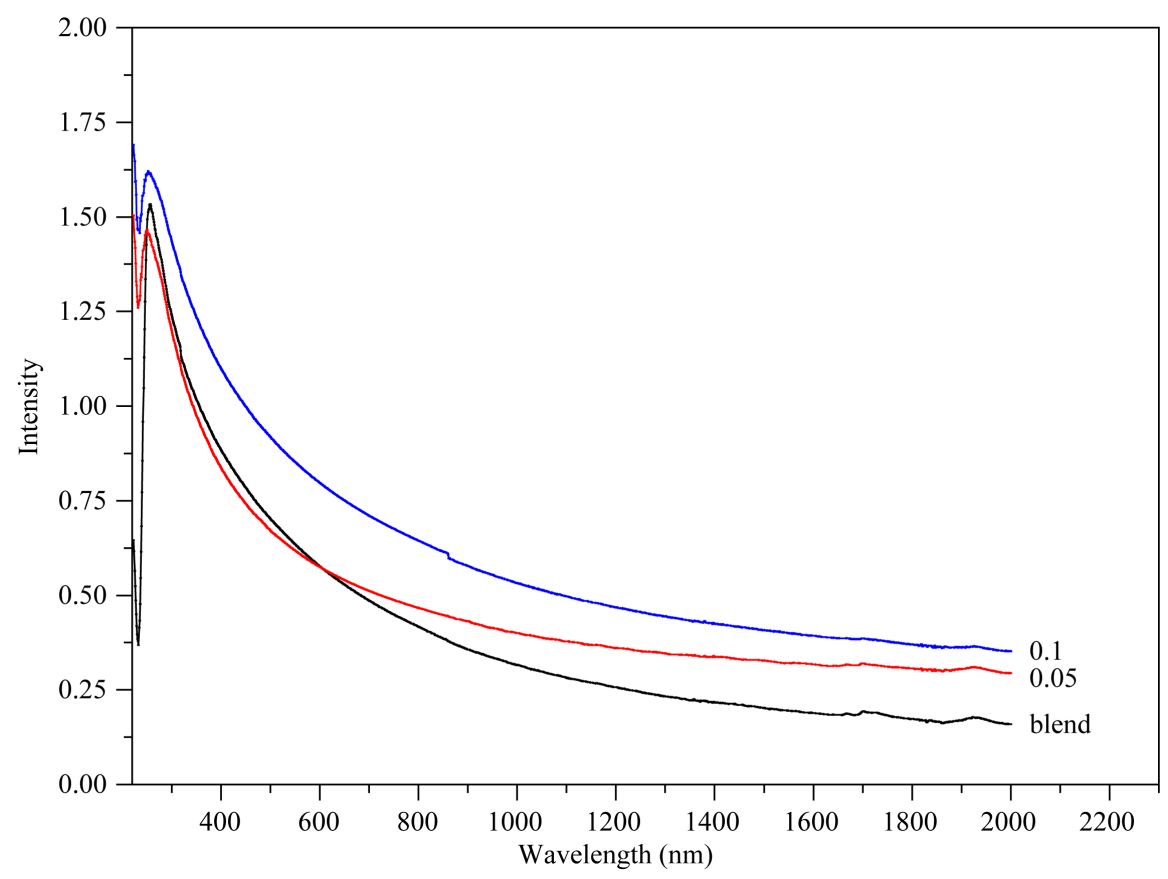

Figure 1. The UV-Vis spectra of PEO/PVDF blend and the blend loaded with 0.05 and 0.1 $\mathrm{Wt} \%$ of SWCNTs. 


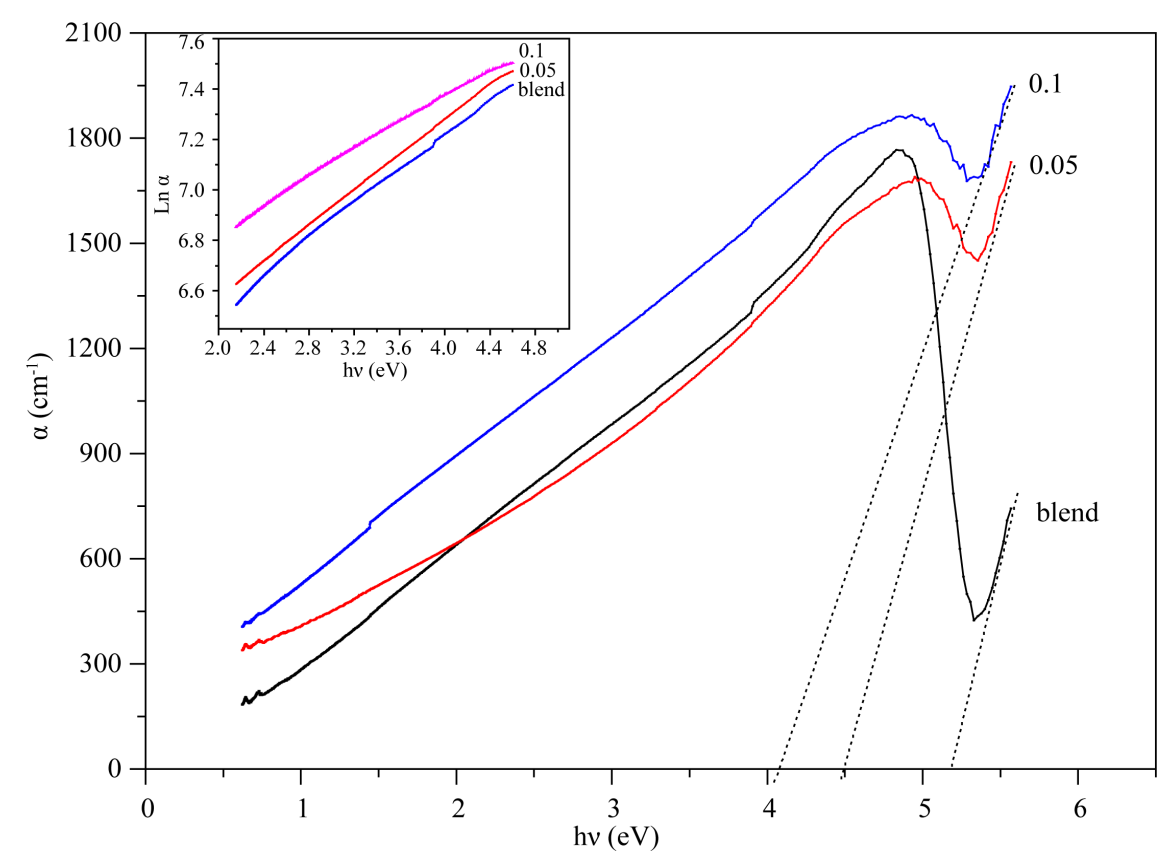

Figure 2. The variation between $(\alpha$ and $\ln \alpha)$ with photon energy $(h v)$ for PEO/PVDF blend loaded by 0.05 and $0.1 \mathrm{Wt} \%$ of SWCNTs.

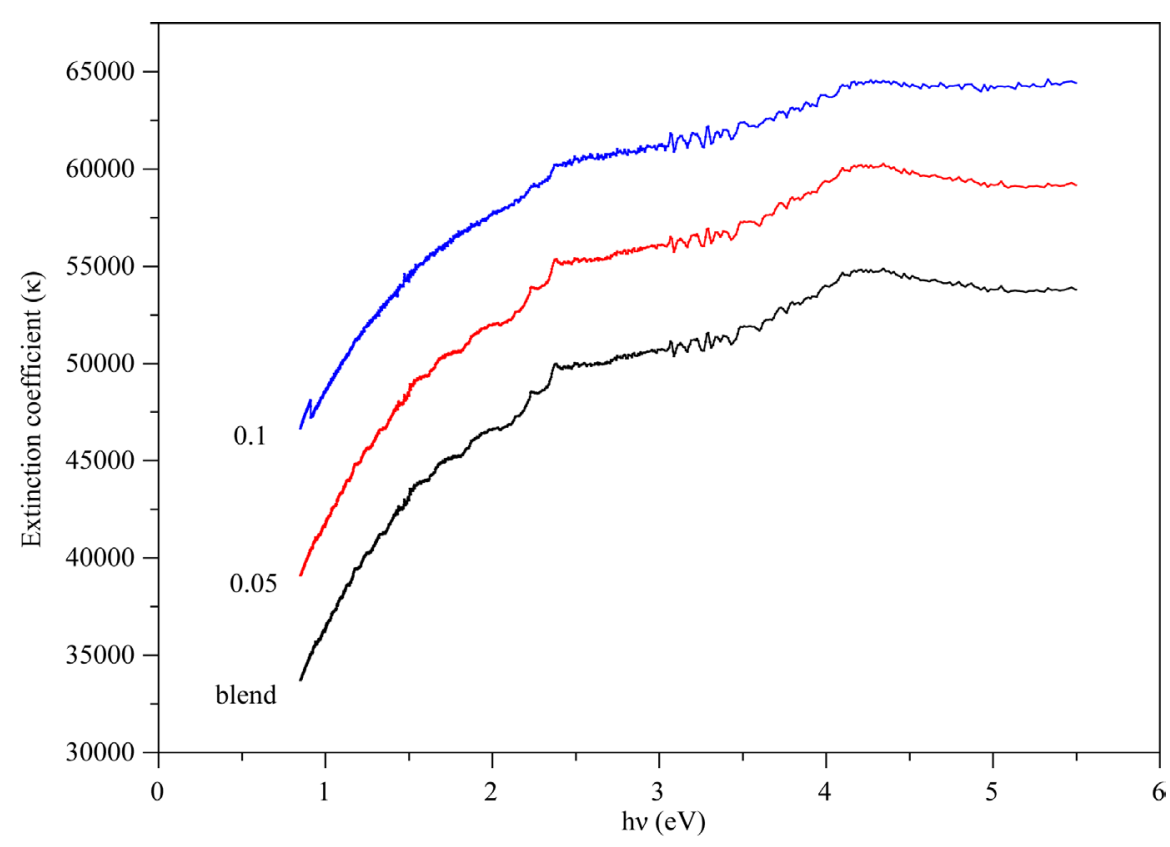

Figure 3. The plot of the extinction coefficient $(k)$ as a function of photon energy $(h v)$ for $\mathrm{PEO} / \mathrm{PVDF}$ blend loaded by 0.05 and $0.1 \mathrm{Wt} \%$ of SWCNTs.

absorption tail related to defects and impurities. Other one is exponential edge region is originates from the disorder in the structure of the material. The last is high absorption region which determines the optical band energy gap. In second region, absorption coefficient lies in the range between $10^{2}$ and $10^{4} \mathrm{~cm}^{-1}$. This follows Urbach equation [18]:

$$
\ln \left(\frac{\alpha}{\alpha_{o}}\right)=\frac{h v}{E_{e}}
$$


where $\alpha_{o}$ is constant and $E_{e}$ is the width of the tail of localized states in the band gap. The inset of Figure 2 shows the relation between $\ln \alpha$ versus $h v$. The straight line suggest that the absorption follows the quadratic relation for inter band transition and hence satisfies the Urbach rule. The values of band tail $E_{e}$ which estimated from the slopes of these lines are 5.18, 4.48 and $4.06 \mathrm{eV}$ for the blend, 0.05 and $0.1 \mathrm{Wt} \%$ of SWCNTs, respectively. The values of $E_{e}$ is decreases with increase of SWCNTs suggesting the decrease in the disorder in the prepared samples.

The optical band gap $\left(E_{g}\right)$ has been determined from absorption coefficient data as a function of $(h v)$ by using the relation [19]:

$$
(\alpha h v)^{2}=C\left(h v-E_{g}\right)
$$

where $c$ is constant and $E_{g}$ is the optical band gap of the sample. The variation of $(\alpha h v)^{2}$ with photon energy $(h v)$ is shown in Figure 4. The values of indirect band gap $\left(E_{g}\right)$ have been calculated by taking the intercept on the $\mathrm{x}$-axis. It is evident from the figure that the values of optical band gap $\left(E_{g}\right)$ decreases with increases SWCNTs concentration from 5.18 to $4.87 \mathrm{eV}$ with increasing of SWCNTs content. The decrease in optical band gap $E_{g}$ indicates an increase in the density of defect states. The decrease in optical band gap could also be discussed on the basis of density of state model proposed by Mott and Davis [20] [21]. The films contain a high concentration of unsaturated bonds or defects are responsible for the presence of localized states in amorphous band gap. This indicates that there are charge transfer complexes arose between the polymer blend and SWCNTs.

\subsection{Raman Spectroscopy}

Figure 5 shows Raman spectra for pristine PEO, PVDF and SWCNTs in the range from 400 to $3200 \mathrm{~nm}$ at room temperature. The main characteristic bands of raw SWCNTs are observed at $1590 \mathrm{~cm}^{-1}$ (G-band) and 1430 $\mathrm{cm}^{-1}$ (D-band). The G-band is an intrinsic feature of carbon nanotubes that is related to vibrations in all $s p$ carbon materials. The most important aspect of the G-band is the characteristic Raman line shape. The first band attributed to graphite is present in Raman shift for SWCNTs bundles as the band at $1580 \mathrm{~cm}^{-1}$ assigned to G band in-plane vibration of the C-C bond. The $\mathrm{G}$ band is a tangential shear mode of carbon atoms that corresponds to the stretching mode in the graphite plane. The other band of SWCNTs bundle at $1341 \mathrm{~cm}^{-1}$ assigned to $\mathrm{D}$ band activated by the presence of disorder in carbon systems. The Raman spectrum also exhibits a band at $2682 \mathrm{~cm}^{-1}$ called the $G^{\prime \prime}$ band and attributed to the overtone of the D band. Some Raman bands are present located at 2888 and $2980 \mathrm{~cm}^{-1}$ called $\mathrm{G}^{\prime}$-band. The frequency of these bands is close to twice that of the D band [22]-[24].

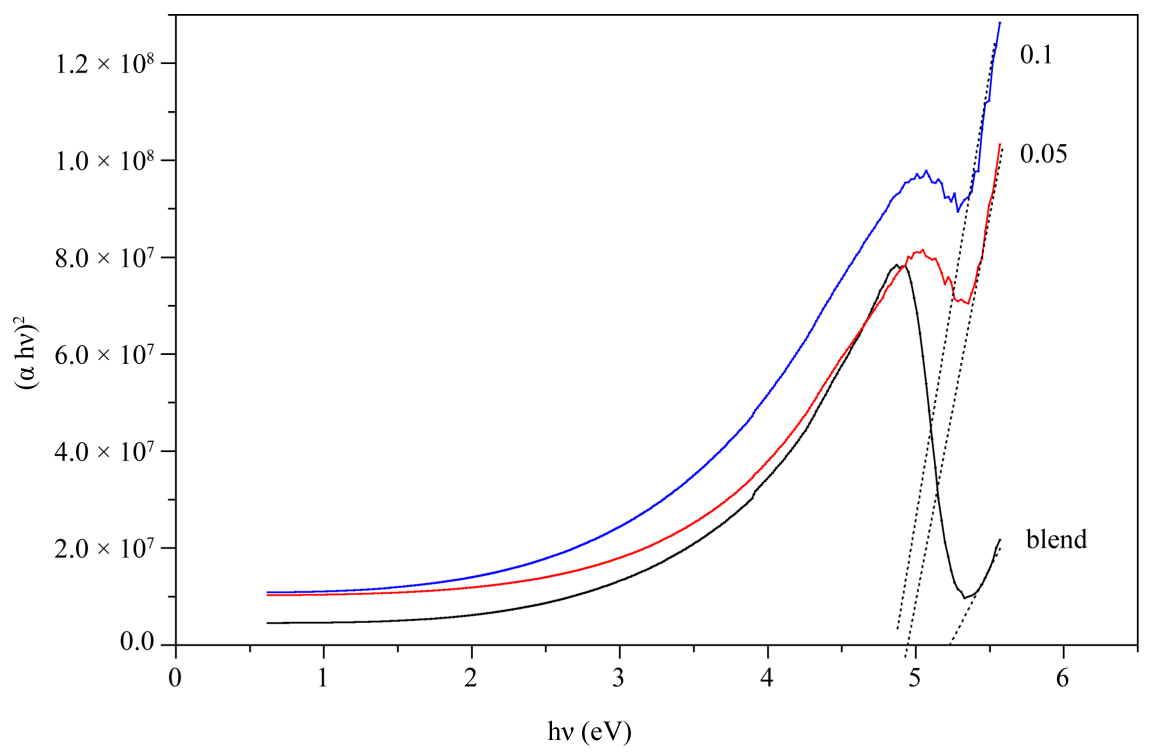

Figure 4. The plots of $(\alpha h v)^{2}$ versus $h v$ for PEO/PVDF blend loaded by 0.05 and $0.1 \mathrm{Wt} \%$ of SWCNTs. 


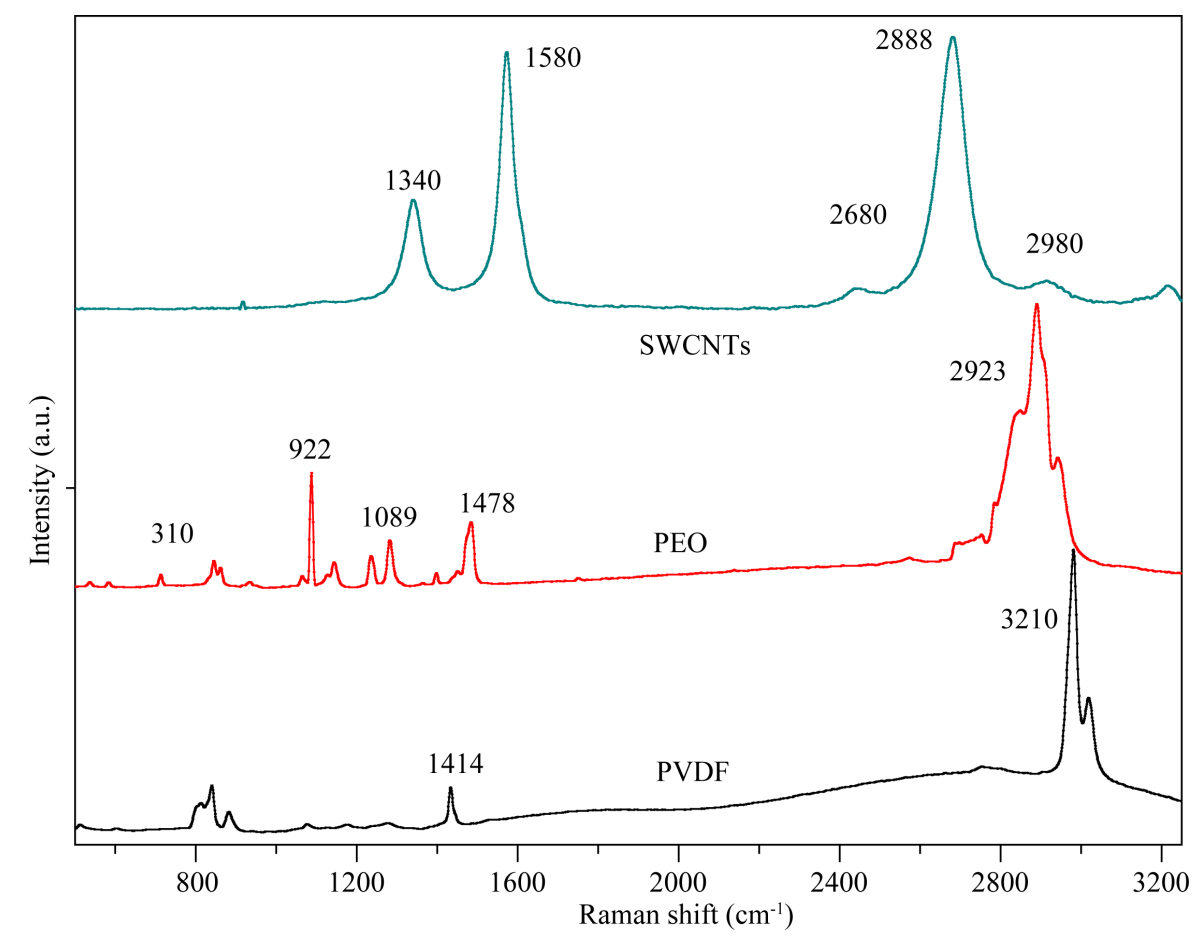

Figure 5. Raman spectra for pristine PEO, PVDF and SWCNTs.

For PEO, the band is observed at $1486 \mathrm{~cm}^{-1}$ can be attributed to the in-phase bending for $\mathrm{CH}_{2}$ group. This mode is active in Raman spectrum and not active in infrared spectrum. The bands observed at 1255 and $1239 \mathrm{~cm}^{-1}$ are assigned to the out-of-phase twisting for $\mathrm{CH}$ group, the band at $\mathrm{cm}^{-1}$ is corresponding to stretching mode of $\mathrm{C}-\mathrm{O}$ group and the band at $1255 \mathrm{~cm}^{-1}$ may be arises from disordered or amorphous portions of the polymer chain. The band at $840 \mathrm{~cm}^{-1}$ is due to hydroxyl (OH) groups in PEO [25].

The Raman shiftsof pure PVDF depicts that the crystal phase is $\alpha$-phase or form II characterized by chain

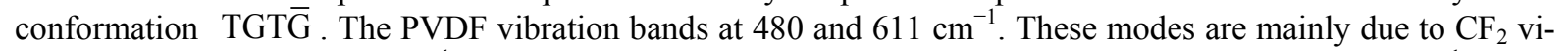
brations. The bands at $513 \mathrm{~cm}^{-1}$ attributed to $\mathrm{CF}_{2}$ bending vibration and higher intensity band at $840 \mathrm{~cm}^{-1}$ due to out of phase combination of $\mathrm{CH}_{2}$ rocking and $\mathrm{CF}_{2}$ stretching mode [26] [27]. These bands are is mainly $\beta$-phase or form I of PVDF

The shift of Raman spectra of pureblend and the blend with 0.05 and $0.1 \mathrm{wt} \%$ are shown in Figure 6 . The spectra present from $1580 \mathrm{~cm}^{-1}$ to $1589 \mathrm{~cm}^{-1}$ for $\mathrm{G}$ band, from $1341 \mathrm{~cm}^{-1}$ to $1346 \mathrm{~cm}^{-1}$ for D band and from $2682 \mathrm{~cm}^{-1}$ to $2689 \mathrm{~cm}^{-1}$ for $G^{\prime \prime}$ band. This shift may be indicates the possibility of SWCNTS-COOH to be attached with $\mathrm{OH}$ group in the side chain of polymer molecules.

\subsection{X-Ray Diffraction (XRD)}

Figure 7 depicts X-ray diffraction spectra of PVDF/PEO blend and the blend incorporated with 0.05 and $0.1 \mathrm{wt} \%$ of SWCNTs in the range $2 \theta=10^{\circ}-80^{\circ}$. The main peaks at $2 \theta \approx 23.92^{\circ}, 42.21^{\circ}$ and $46.62^{\circ}$, referent to the diffractions in planes, $\left(\begin{array}{lll}1 & 1 & 1\end{array}\right),\left(\begin{array}{lll}0 & 4 & 2\end{array}\right)$ and $\left(\begin{array}{lll}1 & 1 & 4\end{array}\right)$, respectively attributed to $\alpha$-crystalline phase of PVDF. The peaks which due to $\beta$-phase of PVDF at $2 \theta=20.10^{\circ}\left(\begin{array}{lll}1 & 1 & 0\end{array}\right)$ and $36.96^{\circ}\left(\begin{array}{lll}2 & 0 & 0\end{array}\right)$ which disappear with adding the filler. For PVDF phases, the peaks at $2 \theta=19.09^{\circ}(020)$ and $39.71^{\circ}(002)$ for $\alpha$-phase, at $2 \theta=20.01^{\circ}(110$ or 200$)$ and $35.48^{\circ}(001)$ for $\beta$-phase and at $2 \theta=26.17^{\circ}(022)$ for $\gamma$-phase are founded [28] [29]. There are two peaks are observed at $2 \theta \approx 18.33^{\circ}$ and $23.25^{\circ}$ corresponding to (120) and (112) attributed to crystallite forms of PEO [30].

On the other hand, all peaks of SWCNTs nanopowder are disappeared in doping samples. This indicates the complete dissolution of the filler in amorphous regions of the polymers revealed the distortion in crystal structure within polymeric matrices or as indicating to dissolution completely of SWCNTs in amorphous domains. A broad of the peaks is increased in broadness with decreased in their intensities suggesting that the amorphousregions. 


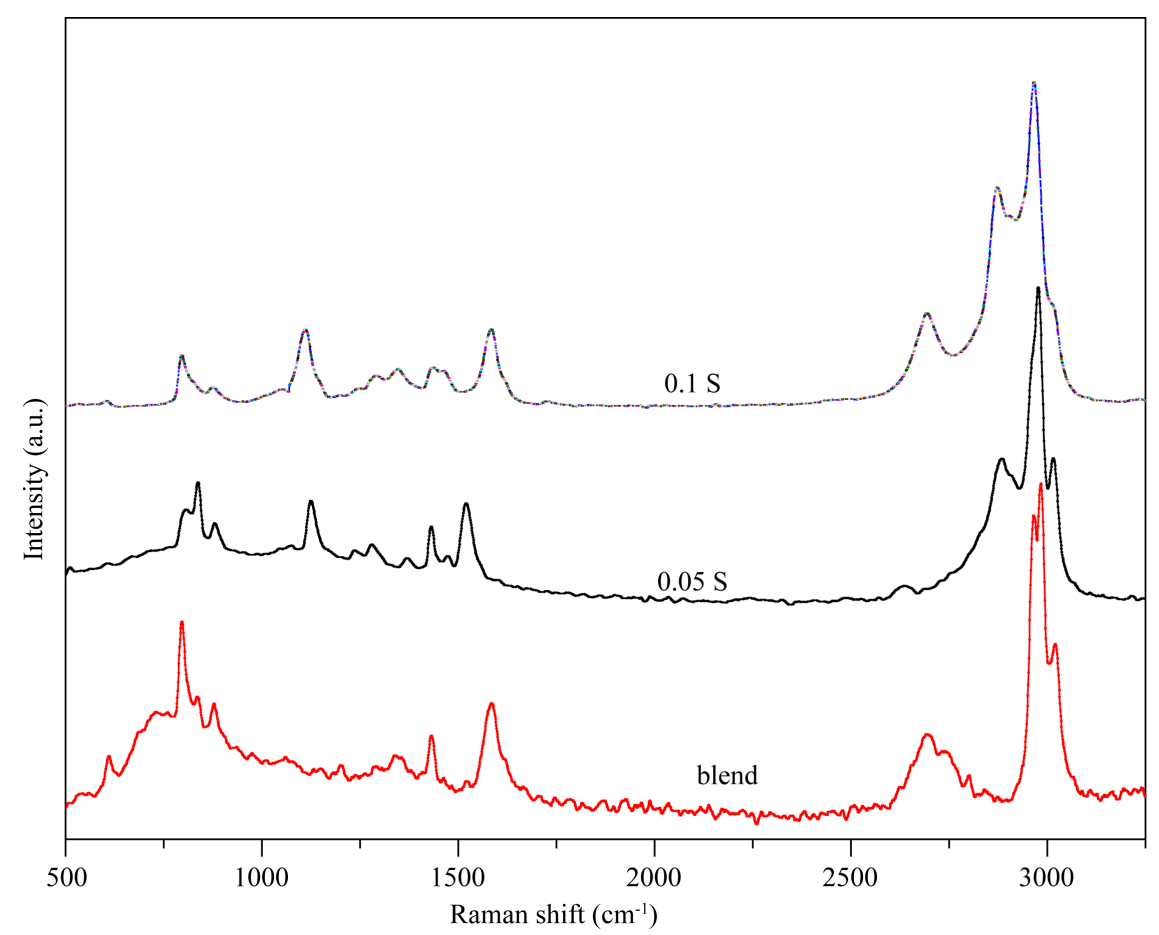

Figure 6. The Raman spectra for PEO/PVDF blend loaded by 0.05 and $0.1 \mathrm{Wt} \%$ of SWCNTs.

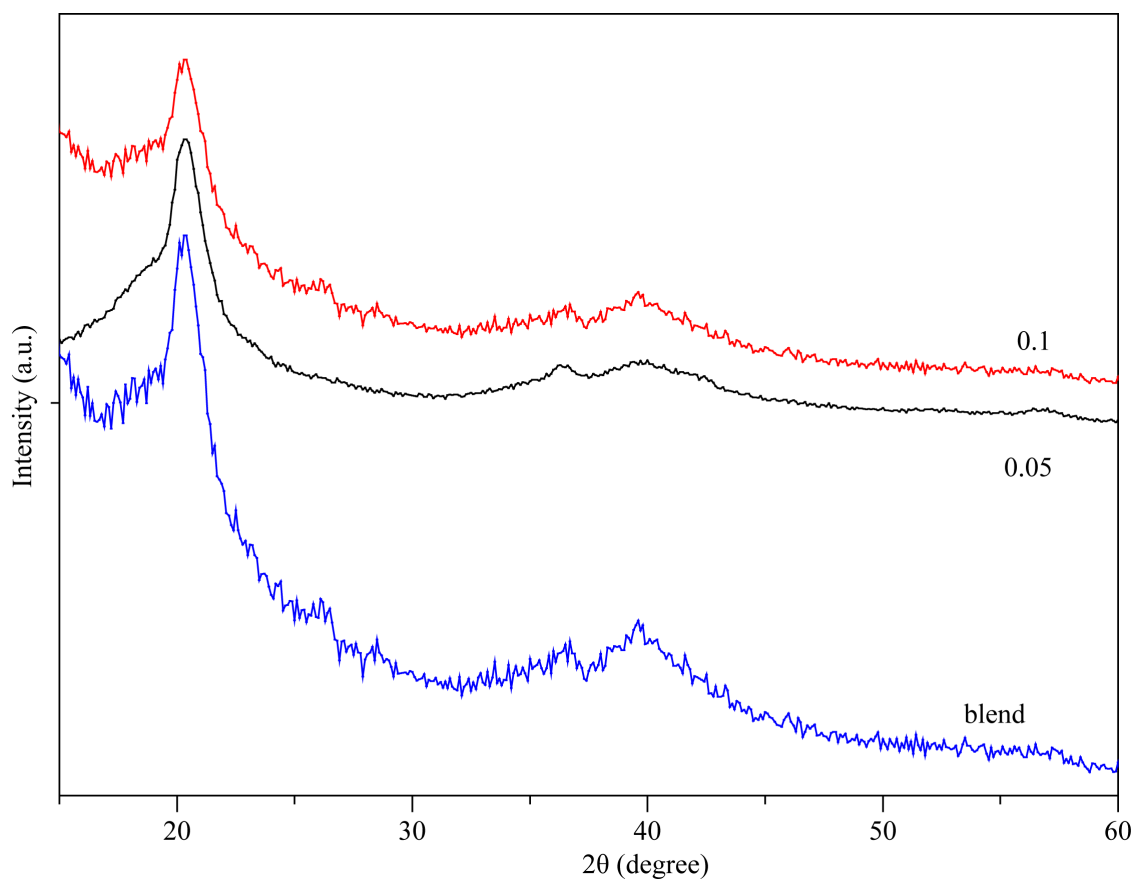

Figure 7. The X-ray diffraction spectra of PVDF/PEO blend and the blend incorporated with 0.05 and $0.1 \mathrm{wt} \%$ of SWCNTs.

It was observed that the reflection of pure blend peaks at $2 \theta=26^{\circ}$ and $27.1^{\circ}$ disappeared which revealed that there is distortion in crystal structure of the blend. The tendency of apparently diminution of crystallinity with the increase of SWCNTs content in blend sample implies a decrease of the number of hydrogen bonds that are formed between PEO and PVDF if present. 
From all previously mentioned results, the interaction between SWCNTs and polymer blend results in decreasing crystallinity with rich amorphous phase. This amorphous nature is responsible for higher conductivity and confirms the complexation between SWCNTs and the polymer blend.

\subsection{Scanning Electron Microscopy (SEM)}

Surface morphology of the prepared films has been studied by scanning electron microscope (SEM). Micrograph in Figure 8 depicts the smooth and free surface of pure PEO/PVDF blend as in previous in literature. After loading SWCNTs, the film surface becomes rough with some small aggregates, but the single rode are well distributed in the entire surface region in polymeric matrices as shown in Figure 9(a) and Figure 9(b). Clear single rods of SWCNTs are observed in the images. The length of the individual rods is short with closed ends. An individual tubes or bundles of small tubes assemble to give thicker bundles. The Images show a twisted bundle consisting of SWCNTs. Furthermore, the nanotubes appear defect free with traces of amorphous carbon (black spots) deposits on the surface of the images.

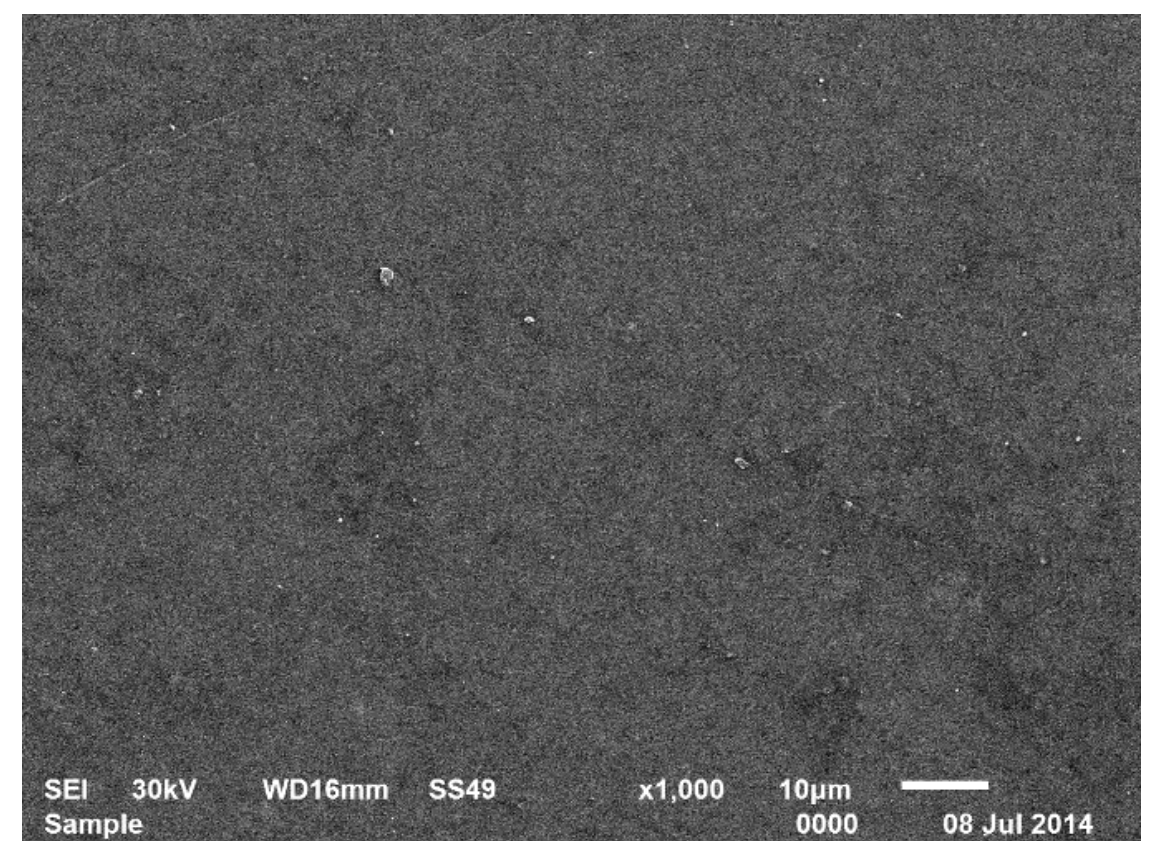

Figure 8. SEM micrograph of pure PEO/PVDF.

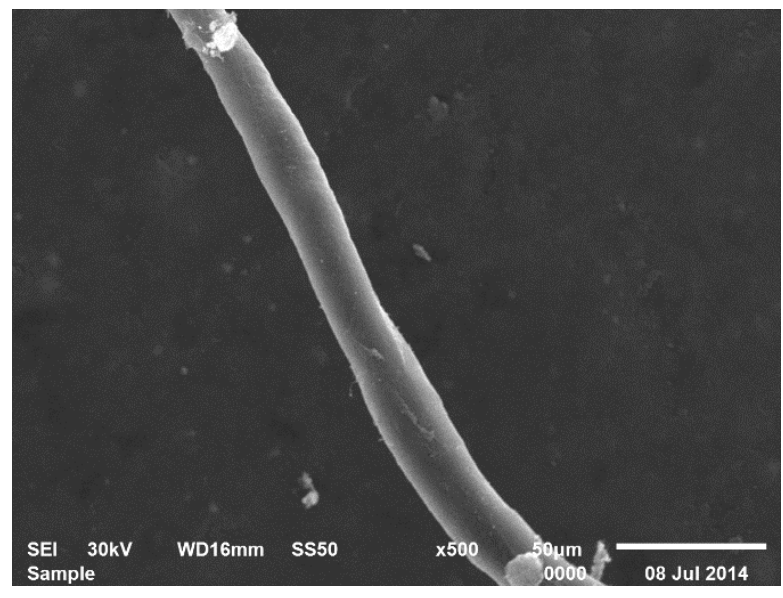

(a)

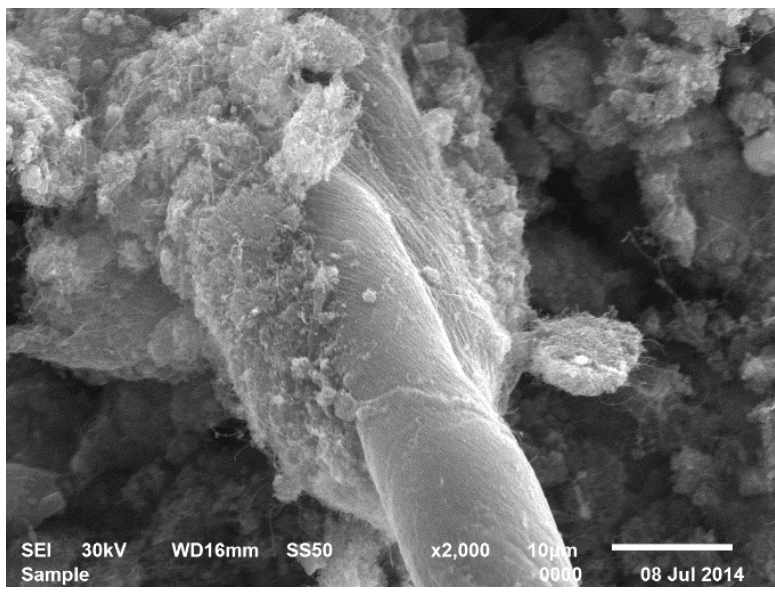

(b)

Figure 9. SEM micrograph of PEO/PVDF blend with SWCNTs. 


\subsection{Transmission Electron Microscopy (TEM)}

Figure 10 shows TEM micrograph of pristine SWCNTs at $0.5 \mu \mathrm{m}$ and $200 \mathrm{~nm}$ magnifications. It can be seen that the surface of purified SWCNTs is very clean and most of the impurity phases, such as amorphous carbon and graphitic nanoparticles are removed during purification of SWCNTs. The diameter of the SWCNTs is $8-14 \mathrm{~nm}$. There are some black spots attributed to amorphous nature carbon. Figure 11 shows the micrograph of SWCNTs dispersion in polymer solution. SWCNTs disperse in polymeric solution results in uniformly dispersing. SWCNTs are implanted uniformly in the polymer solution and have intimate contact with these polymeric matrices. The broken ends of SWCNTs are observed revealing that the nanotubes broke apart rather than being pulled out from the fracture surface indicating the existence of strong interfacial bonding between the CNTs and the polymeric matrices. Moreover, the polymer blend could form a dense layer covering on the images of the nanocomposites showing that some defects like ragged and/or worm eaten on the tube walls. Also, the SWCNTs is arranged in different diameters and wrapped with PEO/PVDF.

\section{Conclusion}

Novel nanocomposites consisted of polyethylene oxide (PEO), and polyvinylidene fluoride (PVDF) loaded by different contents of SWCNTs was prepared and investigated by different techniques. The optical, structural and morphological properties of these nanocomposites were improved by adding SWCNTs. All UV-Vis curves were characterized by the presence of an exponential decay tail at low energy indicating the presence of localized states in the energy band gap. The falling of the edges in lower photon energy region was attributed to the lack of long range order and the irregular fluctuations of internal fields associated with defects in the samples. The Raman shift of G, D and $G^{\prime \prime}$ bands of SWCNTs was observed in all samples. The X-ray revealed decrease in degree of crystallinity is a rich amorphous region in polymeric matrices and complete complexation between PEO/PVDF

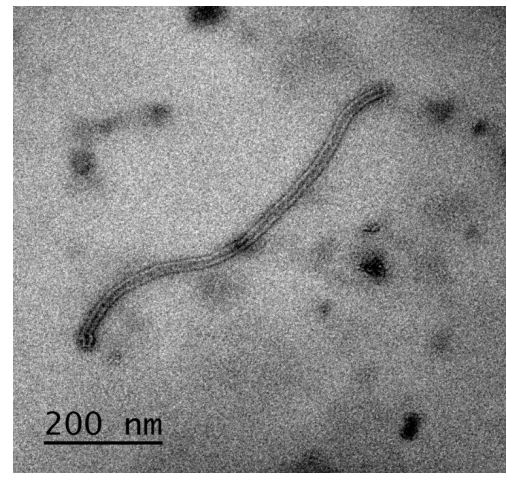

(a)

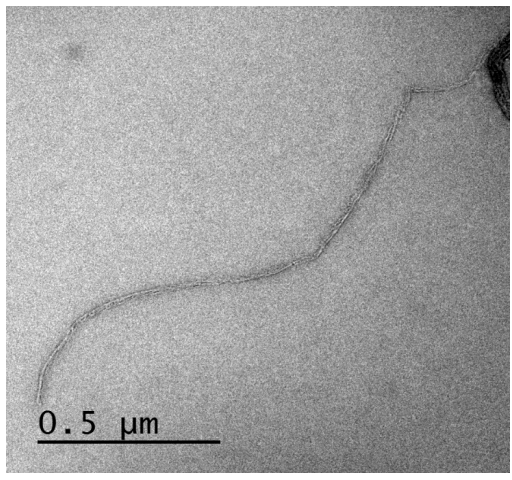

(b)

Figure 10. TEM micrograph of SWCNT with different magnifications.

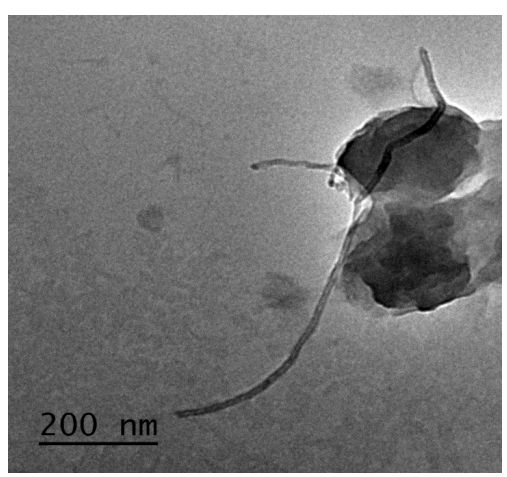

(a)

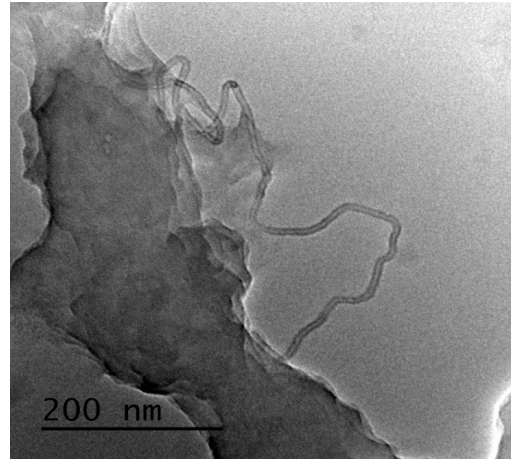

(b)

Figure 11. TEM micrograph of PEO/PVDF blend with (a) $0.05 \mathrm{wt} \%$ and (b) $0.1 \mathrm{wt} \%$ of SWCNTs. 
blend and SWCNTs. SEM images showed the surface rough with single rod after loading SWCNTs. TEM images showed that SWCNTs were dispersed well in polymeric matrices. The broken ends of SWCNTs were revealing that the nanotubes were broken apart rather than being pulled out from the fracture surface. Some black regions in TEM images were attributed to amorphous nature carbon. The prepared nanocomposites are very useful in technical application.

\section{References}

[1] supova, M., Martynkova, G.S. and Barabaszova, K. (2011) Science of Advanced Materials, 3, 1-25.

[2] Tjong, S.C. (2006) Materials Science and Engineering: R: Reports, 53, 73-197. http://dx.doi.org/10.1016/j.mser.2006.06.001

[3] Utracki, L.A. (2007) Polymers for Advanced Technologies, 18, 1-37. http://dx.doi.org/10.1002/pat.852

[4] Chen, C.Q., Pei, Y.T. and De Hosson, J.T.M. (2012) Scripta Materialia, 67, 947-950. http://dx.doi.org/10.1016/j.scriptamat.2012.08.029

[5] Wu, Z., Zhang, Y.W., Jhon, M.H., Gao, H. and Srolovitz, D.J. (2012) Nano Letters, 12, 910-914. http://dx.doi.org/10.1021/nl203980u

[6] Sha, Z.D., He, L.C., Xu, S., Pei, Q.X., Liu, Z.S., Zhang, Y.W. and Wang, T.J. (2014) Scripta Materialia, 93, 36-39. http://dx.doi.org/10.1016/j.scriptamat.2014.08.025

[7] Iijima, S. (1991) Nature, 354, 56-58. http://dx.doi.org/10.1038/354056a0

[8] Dhand, C., Arya, S.K., Singh, S.P., Singh, B.P., Datta, M. and Malhotra, B.D. (2008) Carbon, 46, 1727-1735. http://dx.doi.org/10.1016/j.carbon.2008.07.028

[9] Popov, V.N. (2004) Materials Science and Engineering: R: Reports, 43, 61-102. http://dx.doi.org/10.1016/j.mser.2003.10.001

[10] Odom, T.W. (2001) Australian Journal of Chemistry, 54, 601.

[11] Paiva, M.C., Zhou, B., Fernando, K.A.S., Lin, Y., Kennedy, J.M. and Sun, Y.P. (2004) Carbon, 42, 2849-2854. http://dx.doi.org/10.1016/j.carbon.2004.06.031

[12] Liu, L., Barber, A.H., Nuriel, S. and Wagner, H.D. (2005) Advanced Functional Materials, 15, 975-980. http://dx.doi.org/10.1002/adfm.200400525

[13] Dow, J.D. and Redfield, D. (1972) Physical Review B, 5, 594. http://dx.doi.org/10.1103/PhysRevB.5.594

[14] Abdelrazek, E.M. (2008) Physica B, 403, 2137-2142. http://dx.doi.org/10.1016/j.physb.2007.11.029

[15] Reddy, C.V.S., Zhu, Q.Y., Mai, L.Q. and Chen, W. (2006) Journal of Applied Electrochemistry, 36, 1051-1056. http://dx.doi.org/10.1007/s10800-006-9158-3

[16] Sharma, P., Sharma, V. and Katyl, S.C. (2006) Chalcogenide Letters, 3, 73-79.

[17] Wood, D.L. and Tauc, J. (1972) Physical Review B, 5, 3144. http://dx.doi.org/10.1103/PhysRevB.5.3144

[18] Urbach, F. (1953) Physical Review, 92, 1324. http://dx.doi.org/10.1103/PhysRev.92.1324

[19] Altaf, M. and Chaudhry, M.A. (2000) Journal of the Korean Physical Society, 36, 265.

[20] Mott, N.F. and Davis, E.A. (1971) Electronic Processes in Non-Crystalline Solids. Clarendon Press, Oxford.

[21] Dwivedi, D.K., Pathak, H.P., Shukla, R.K. and Kumar, A. (2013) American Journal of Materials Science and Engineering, 1, 46-49.

[22] Dresselhaus, M.S., Dresselhaus, G., Saito, R. and Jorio, A. (2005) Physics Reports, 409, 47-99. http://dx.doi.org/10.1016/j.physrep.2004.10.006

[23] Dresselhaus, M.S., Dresselhausc, G., Jorio, A., Filho, A.G.S. and Saito, R. (2002) Carbon, 40, 2043-2061. http://dx.doi.org/10.1016/S0008-6223(02)00066-0

[24] Dresselhaus, M.S. and Eklund, P.C. (2000) Advances in Physics, 49, 705-814. http://dx.doi.org/10.1080/000187300413184

[25] Maxfield, J. and Shepherd, I.W. (1975) Polymer, 16, 505-509. http://dx.doi.org/10.1016/0032-3861(75)90008-7

[26] Mattsson, B., Ericson, H., Torell, L.M. and Sundholm, F. (2000) Electrochimica Acta, 45, 1405-1408. http://dx.doi.org/10.1016/S0013-4686(99)00351-5

[27] Mattsson, B., Ericson, H., Torell, L.M. and Sundholm, F. (1999) Journal of Polymer Science Part A: Polymer Chemistry, 37, 3317-3327. http://dx.doi.org/10.1002/(SICI)1099-0518(19990815)37:16<3317::AID-POLA30>3.0.CO;2-\#

[28] Lebedev, S.M., Gefle, O.S. and Tkachenko, S.N. (2011) Russian Physics Journal, 54, 679-685. 
http://dx.doi.org/10.1007/s11182-011-9669-1

[29] Wang, Y., Wang, J., Wang, F., Li, S. and Xiao, J. (2008) Polymer Bulletin, 60, 647-655.

[30] Mihaylova, M.D., Krestev, V.P., Kresteva, M.N., Amzil, A. and Berlinova, I.V. (2001) European Polymer Journal, 37, 233-239. http://dx.doi.org/10.1016/S0014-3057(00)00103-8 